\title{
Accuracy of Parenchymal Cerebral Blood Flow Measurements Using Pseudocontinuous Arterial Spin-Labeling in Healthy Volunteers
}

\author{
K. Ambarki, A. Wåhlin, L. Zarrinkoob, R. Wirestam, J. Petr, J. Malm, and A. Eklund
}

O-

\begin{abstract}
BACKGROUND AND PURPOSE: The arterial spin-labeling method for CBF assessment is widely available, but its accuracy is not fully established. We investigated the accuracy of a whole-brain arterial spin-labeling technique for assessing the mean parenchymal CBF and the effect of aging in healthy volunteers. Phase-contrast MR imaging was used as the reference method.
\end{abstract}

MATERIALS AND METHODS: Ninety-two healthy volunteers were included: 49 young (age range, $20-30$ years) and 43 elderly (age range, 65-80 years). Arterial spin-labeling parenchymal CBF values were averaged over the whole brain to quantify the mean $p$ CBF $_{A S L}$ value. Total $\mathrm{CBF}$ was assessed with phase-contrast MR imaging as the sum of flows in the internal carotid and vertebral arteries, and subsequent division by brain volume returned the $\mathrm{PCBF}_{\mathrm{PCMRI}}$ value. Accuracy was considered as good as that of the reference method if the systematic difference was less than $5 \mathrm{~mL} / \mathrm{min} / 100 \mathrm{~g}$ of brain tissue and if the $95 \%$ confidence intervals were equal to or better than $\pm 10 \mathrm{~mL} / \mathrm{min} / 100 \mathrm{~g}$.

RESULTS: $\mathrm{pCBF}_{\mathrm{ASL}}$ correlated to $\mathrm{pCBF}_{\mathrm{PCMRI}}(r=0.73 ; P<.001)$. Significant differences were observed between the $\mathrm{PCBF} \mathrm{ASL}_{\text {L }}$ and $\mathrm{PCBF} \mathrm{PCMRI}_{\mathrm{P}}$ values in the young $(P=.001)$ and the elderly $(P<.001)$ volunteers. The systematic differences (mean \pm 2 standard deviations) were $-4 \pm$ $14 \mathrm{~mL} / \mathrm{min} / 100 \mathrm{~g}$ in the young subjects and $6 \pm 12 \mathrm{~mL} / \mathrm{min} / 100 \mathrm{~g}$ in the elderly subjects. Young subjects showed higher values than the

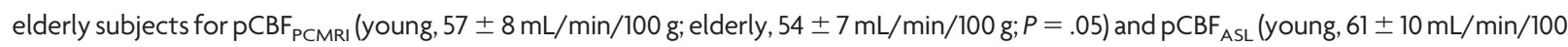
g; elderly, $48 \pm 10 \mathrm{~mL} / \mathrm{min} / 100 \mathrm{~g} ; P<.001)$.

CONCLUSIONS: The limits of agreement were too wide for the arterial spin-labeling method to be considered satisfactorily accurate, whereas the systematic overestimation in the young subjects and underestimation in the elderly subjects were close to acceptable. The age-related decrease in parenchymal CBF was augmented in arterial spin-labeling compared with phase-contrast MR imaging.

ABBREVIATIONS: $A S L=$ arterial spin-labeling; $\mathrm{HE}=$ healthy elderly; $\mathrm{HY}=$ healthy young; $\mathrm{PCASL}=$ pseudocontinuous $\mathrm{ASL} ; \mathrm{PCBF}=$ parenchymal $\mathrm{CBF} ; \mathrm{PCMRI}=$ phase-contrast MRI; $\mathrm{VA}=$ vertebral artery

sing well-established perfusion imaging techniques, such as PET, SPECT, or other techniques such as perfusion CT, cerebral blood flow can be quantified within parenchymal tissue and ex-

Received December 20, 2014; accepted after revision February 16, 2015.

From the Department of Radiation Sciences (K.A., A.W., A.E.), Centre for Biomedical Engineering and Physics (K.A., A.E.), Center for Functional Brain Imaging (A.W., A.E.), and Department of Clinical Neuroscience (L.Z., J.M.), Umeå University, Umeå, Sweden; Department of Medical Radiation Physics (R.W.), Lund University, Lund, Sweden; and PET Center (J.P.), Institute of Radiopharmaceutical Cancer Research, Helmholtz-Zentrum Dresden-Rossendorf, Dresden, Germany.

This work was supported by Swedish Research Council (grants 621-2011-5216 and 13514), European Union Objective 2 Norra Norrland (project 148273 CMTF), County Council of Västerbotten and Swedish Heart and Lung Foundation (grant 20110383), and the Swedish Brain Foundation.

Please address correspondence to K. Ambarki, PhD, Umeå Hospital, Department of Radiation Sciences, S-901 87 Umeå, Sweden; e-mail: khalid.ambarki@vll.se

-- Indicates open access to non-subscribers at www.ajnr.org

Indicates article with supplemental on-line photo.

EBM Evidence-Based Medicine Level 2.

http://dx.doi.org/10.3174/ajnr.A4367 pressed in milliliters per minute per $100 \mathrm{~g}$ of brain tissue $(\mathrm{mL} / \mathrm{min} /$ $100 \mathrm{~g}$ ). These methods require injection of a contrast agent or a radioactive tracer. However, radiotracers are associated with exposure to ionizing radiation, CT contrast agents are nephrotoxic, and perfusion studies of this kind cannot be repeated until the contrast medium or tracer disappears. Using arterial spin-labeling (ASL) MR imaging, ${ }^{1}$ it is possible to assess parenchymal CBF (pCBF) noninvasively. Recent developments have enabled quantitative assessment of whole-brain perfusion with ASL within a few minutes. ${ }^{2,3}$ The accuracy of pCBF estimates obtained by using ASL, however, is still a subject of discussion. ${ }^{4}$ Age- and sex-related differences in $\mathrm{pCBF}$ have been found by using ASL, PET, and SPECT. ${ }^{5-10}$ However, these effects are still not fully understood, and no consensus has been established from previously published data. ${ }^{11,12}$

Total CBF is defined by the 4 arteries that supply the brain (ie, the internal carotid arteries and the vertebral arteries [VAs]). The blood flow of these arteries, and thus the total CBF, can be measured with good accuracy at the level of the foramen magnum by 
using 2D phase-contrast MR imaging (PCMRI). ${ }^{13,14}$ Using highresolution morphologic $\mathrm{MR}$ imaging data and postprocessing software, the total volume of the brain parenchymal tissue can be assessed. Total CBF can be obtained accurately with PCMRI (shown here as $\mathrm{PCBF}_{\mathrm{PCMRI}}$ values), ${ }^{14}$ and brain parenchymal volume can be measured accurately ${ }^{15}$ from the T1 sequence. By dividing flow by volume, $\mathrm{pCBF}_{\mathrm{PCMRI}}$ can be estimated with expected good accuracy and used as a reference to evaluate the accuracy of pCBF obtained via ASL ( $\left.\mathrm{pCBF}_{\mathrm{ASL}}\right)$.

The aim of this study was to investigate the accuracy of a clinically implemented pseudocontinuous ASL method for assessing pCBF in 92 healthy individuals by using PCMRI as the reference method. The effects of aging and sex on pCBF were assessed by using both methods, and the results were compared.

\section{MATERIALS AND METHODS Subjects}

A total of 111 subjects, recruited by advertisement in a daily newspaper, were included in this prospective study. The subjects were defined as healthy if they had no neurologic or cardiac disease, hypertension, peripheral vascular disease, or renal disease. Eleven subjects were excluded after the physical examination because of a MiniMental State Examination score of $<28$ points $(n=3),{ }^{16}$ electrocardiogram changes $(n=1)$, a blood pressure of $>160 / 90 \mathrm{~mm} \mathrm{Hg}(n=$ $1)$, or neurologic issues $(n=6)$. After the MR imaging examination, 8 subjects were excluded because of claustrophobia $(n=3)$ or technical problems or missing MR imaging data $(n=5)$. The remaining 92 healthy subjects were categorized in 1 of 2 different age groups (ie, 49 subjects in the healthy young [HY] group [age range, 20-30 years; mean age \pm standard deviation, $25 \pm 2$ years; 27 women] and 43 subjects in the healthy elderly [HE] group [age range, 65-80 years; mean age \pm standard deviation, $71 \pm 4$ years; 23 women]). In addition, the 92 subjects were classified according to sex (ie, the study group included 50 healthy women and 42 healthy men). The research protocol used in this study was approved by the ethical review board of Umeå University. Each patient provided oral and written informed consent.

\section{MR Imaging}

Each subject was scanned by using a 3T MR imaging unit (Discovery MR 750; GE Healthcare, Milwaukee, Wisconsin) supplied with a 32-channel head coil.

Three-dimensional time-of-flight angiography was performed to visualize the ICAs and the VAs. TOF angiography was used to position a perpendicular PCMRI plane at the cervical (C1-C2) level. The 2D PCMRI data were acquired with the following parameters: TR, 9 ms; TE, $5 \mathrm{~ms}$; section thickness, $5 \mathrm{~mm}$; flip angle, $15^{\circ}$; FOV, $180 \times$ $180 \mathrm{~mm}^{2}$; acquisition matrix, $512 \times 512$; in-plane resolution, $0.35 \times$ $0.35 \mathrm{~mm}^{2}$; views per segment, 6; velocity encoding, $70 \mathrm{~cm} / \mathrm{s}$; and NEX, 2. Thirty-two velocity-coded and magnitude images throughout the entire cardiac cycle were collected. A peripheral pulse signal was used for retrospective cardiac gating. The acquisition time of the PCMRI was approximately 2 minutes 30 seconds, depending on the subject's heart rate.

Whole-brain perfusion data were obtained by using a $3 \mathrm{D}$ pseudocontinuous ASL (pCASL) method implemented by the manufacturer (Appendix). In summary, the pCASL was applied, followed by an interleaved 3D stack of spiral fast spin-echo readout with background suppression. ${ }^{3}$ The pCASL parameters were as follows: sampling points on 8 spirals, 512; FOV, $240 \times 240$ $\mathrm{mm}^{2}$; true in-plane resolution, $3.75 \mathrm{~mm}^{17-19}$; reconstructed matrix, $128 \times 128$; TR, $4674 \mathrm{~ms}$; TE, $10 \mathrm{~ms}$; NEX, 3; section thickness, $4 \mathrm{~mm}$; labeling plane positioned at the base of the cerebellum; labeling duration, $1500 \mathrm{~ms}$; postlabeling delay, $1525 \mathrm{~ms}^{20}$; sections covering the whole brain, $40-44$; control/label pairs, 30; and acquisition time, 4 minutes 31 seconds.

High-resolution T1-weighted data for assessing brain parenchymal volume were collected by using a sagittal 3D fast-spoiled gradient-echo sequence to image the whole brain with $176 \mathrm{sec}$ tions, a section thickness of $1 \mathrm{~mm}$, a TR of $7 \mathrm{~ms}$, a TE of $2 \mathrm{~ms}$, a flip angle of $10^{\circ}$, a FOV of $250 \times 250 \mathrm{~mm}$, an acquisition matrix of $256 \times 256$, and an acquisition time of 5 minutes 20 seconds.

\section{MR Imaging Data Postprocessing and Analysis}

Brain Parenchymal Tissue Segmentation. The T1-weighted data were processed by using the VBM8 toolbox (http://dbm.neuro. uni-jena.de/vbm.html) and default parameters of SPM8 software (http://www.fil.ion.ucl.ac.uk/spm/) by using Matlab R2013b (MathWorks, Natick, Massachusetts). The segmentation method of VBM8 is based on an adaptive maximum a posteriori approach, ${ }^{21}$ and tissue compartments were classified into gray matter, white matter, and CSF. GM and WM segmentations were inspected visually to ensure quality of the segmentation. No severe missegmentation of brain parenchymal tissue was observed, and therefore no data were omitted from the analysis. However, in a few of the elderly subjects, the periventricular WM was misclassified as GM, but the segmentation did not alter the whole-brain segmentation, and no manual correction had to be performed.

ASL Measurement of Parenchymal Cerebral Blood Flow. The pCASL pCBF maps (in $\mathrm{mL} / \mathrm{min} / 100 \mathrm{~g}$ ) were computed by the postprocessing FuncTool software (version 10.4.04; GE Healthcare) that was based on a general kinetic model for ASL. ${ }^{22}$ The details of the manufacturer's implementation method to quantify the pCBF maps are shown in the Appendix.

Using the SPM8 software, GM and WM masks were co-registered to the ASL data and down-sampled to the same pixel size as that of the reconstructed ASL data. The GM and WM masks were then smoothed in-plane with a Gaussian kernel $\left(3.25 \times 3.25 \mathrm{~mm}^{2}\right.$ full width at half maximum) to create a resolution identical to the true spatial resolution of ASL (On-line Fig 1). Erosion was applied to exclude the 2 outer pixel layers from the brain mask (GM and WM) to avoid ASL artifacts and inclusion of the skull. Each pixel in the brain mask contains the volume fractions of $\mathrm{GM}\left(F_{\mathrm{GM}}\right)$ and $\mathrm{WM}\left(F_{\mathrm{WM}}\right)$. The brain parenchymal volume was calculated as the sum of the GM and WM volumes. The mean pCBF from the ASL data $\left(\mathrm{pCBF}_{\mathrm{ASL}}\right)$ was estimated by using equation 1 :

$$
\mathrm{pCBF}_{\mathrm{ASL}}=\frac{\sum_{i=1}^{i=\mathrm{n}} \mathrm{CBF}(i)}{\sum_{i=1}^{i=\mathrm{n}}\left(F_{\mathrm{GM}}(i)+F_{\mathrm{WM}}(i)\right)},
$$

AJNR Am J Neuroradiol 36:1816-21 Oct 2015 www.ajnr.org 
where $F_{\mathrm{GM}}$ and $F_{\mathrm{WM}}$ are the volume fractions of $\mathrm{GM}$ and $\mathrm{WM}$, respectively, $\mathrm{CBF}(i)$ is the cerebral blood flow $(\mathrm{mL} / \mathrm{min} / 100 \mathrm{~g}$ of brain tissue) within the $i$ th ASL pixel, and $n$ is the number of pixels that contain brain tissue $\left(F_{\mathrm{GM}}+F_{\mathrm{WM}}>0 \%\right)$. Our aim was to estimate the perfusion in the entire parenchymal tissue. No partial volume correction was thus necessary to separate perfusion signal from individual WM and GM voxels.

PCMRI Measurement of Vessel Velocity and Parenchymal Cerebral Blood Flow. PCMRI data were analyzed by using Segment software version 1.8 (Mediviso, Lund, Sweden). The magnitude images were used to delineate manually the cross-section areas of the ICAs and VAs. The positions and sizes of the cross-section areas were kept constant during the cardiac cycle. For each vessel, the flow rate was computed as the mean velocity multiplied by the cross-section area.

The blood flow rates of the bilateral ICAs and VAs were summed, and the derived blood flow rate was averaged over the cardiac cycle to estimate the total CBF (reported in milliliters per minute). Thereafter, the parenchymal cerebral blood flow from PCMRI ( $\mathrm{pCBF}_{\text {PCMRI }}$ ) was calculated in milliliters per minute per $100 \mathrm{~g}$ of brain tissue by using equation 2 :

$$
\mathrm{pCBF}_{\mathrm{PCMRI}}=\frac{\mathrm{tCBF}}{\rho \times \mathrm{BPV}} \times 100,
$$

where tCBF is total CBF, BPV is brain parenchymal volume, and $\rho$ is the brain tissue density $(1.05 \mathrm{~g} / \mathrm{mL}){ }^{23}$

Furthermore, the velocity of blood in the labeling plane directly affects the labeling efficiency of the pCASL and thus also the pCBF quantification. ${ }^{3,13}$ To investigate the effect of the mean velocity of the bilateral ICAs and VAs on the ASL data, mean velocities were computed and correlated to the difference between $\mathrm{pCBF}_{\mathrm{PCMRI}}$ and $\mathrm{pCBF} \mathrm{ASL}_{\mathrm{A}}$.

\section{Statistical Analysis}

SPSS Statistics version 18 (IBM, Armonk, New York) was used to perform statistical analysis. Variables were expressed as means \pm standard deviation. The Shapiro-Wilk test was used to test the normal distribution of the measured parameters. Differences between the groups were investigated by using the unpaired Student $t$ test. For the comparison between $\mathrm{pCBF}_{\mathrm{ASL}}$ and $\mathrm{pCBF}_{\mathrm{PCMRI}}$ values, linear regression analysis and BlandAltman plots were used. ${ }^{24}$ Differences between the $\mathrm{pCBF}_{\mathrm{PCMRI}}$ and $\mathrm{pCBF}_{\mathrm{ASL}}$ values were tested by using the paired Student $t$ test. The accuracy was defined as the systematic bias and the random difference (mean difference \pm 2 standard deviations) between the 2 methods. We considered the accuracy of ASL-based pCBF measurement to be good if the systematic difference against the reference method was $<5 \mathrm{~mL} / \mathrm{min} / 100$ $\mathrm{g}$ and if the randomized difference was less than or equal to $\pm 10 \mathrm{~mL} /$ $\mathrm{min} / 100 \mathrm{~g}$, which corresponds to the limits of agreement previously shown for repeated measurements with PCMRI ${ }^{14}$ and for repeated measurements with ASL. ${ }^{19}$ A $P$ value of $<.05$ was considered statistically significant.

\section{RESULTS}

\section{Comparison of PCMRI and ASL}

The pCBF values obtained by PCMRI and ASL are shown in the Table, and a comparison between the $\mathrm{pCBF}_{\mathrm{PCMRI}}$ and $\mathrm{pCBF}_{\mathrm{ASL}}$ values is displayed in the Figure. There was a significant correlation between $\mathrm{pCBF}_{\mathrm{PCMRI}}$ and $\mathrm{pCBF}_{\mathrm{ASL}}$ values $(r=0.73 ; P<.001)$. Corresponding correlation coefficients $(r)$ when the HY and HE groups were compared separately were $0.73(P<.001)$ and $0.78(P<.001)$, respectively. As shown in the Table, there was a significant difference between $\mathrm{pCBF}_{\mathrm{ASL}}$ and $\mathrm{pCBF}_{\mathrm{PCMRI}}$ for $\mathrm{HE}(P<.001)$ and $\mathrm{HY}(P=$ $.001)$ subjects but not for the whole group $(P=.34)$. For all subjects, the mean bias and the limits of agreement between the 2 methods were $1 \pm 16 \mathrm{~mL} / \mathrm{min} / 100 \mathrm{~g}$ (mean \pm 2 standard deviations). The mean bias $\left(\mathrm{pCBF}_{\mathrm{PCMRI}}-\mathrm{pCBF}_{\mathrm{ASL}}\right)$ showed an underestimation by ASL in $\mathrm{HE}$ subjects $(6 \pm 12 \mathrm{~mL} / \mathrm{min} / 100 \mathrm{~g})$ and an overestimation in HY subjects $(-4 \pm 14$ $\mathrm{mL} / \mathrm{min} / 100 \mathrm{~g})$, whereas it was similar for healthy men and women $(2 \pm 19$ and $0 \pm$ $16 \mathrm{~mL} / \mathrm{min} / 100 \mathrm{~g}$, respectively; $P=.256$ ).

The difference between $\mathrm{pCBF}_{\mathrm{PCMRI}}$ and $\mathrm{pCBF}_{\mathrm{ASL}}$ showed significant corre-

Note:- HW indicates healthy women; HM, healthy men.

a Value is significant.
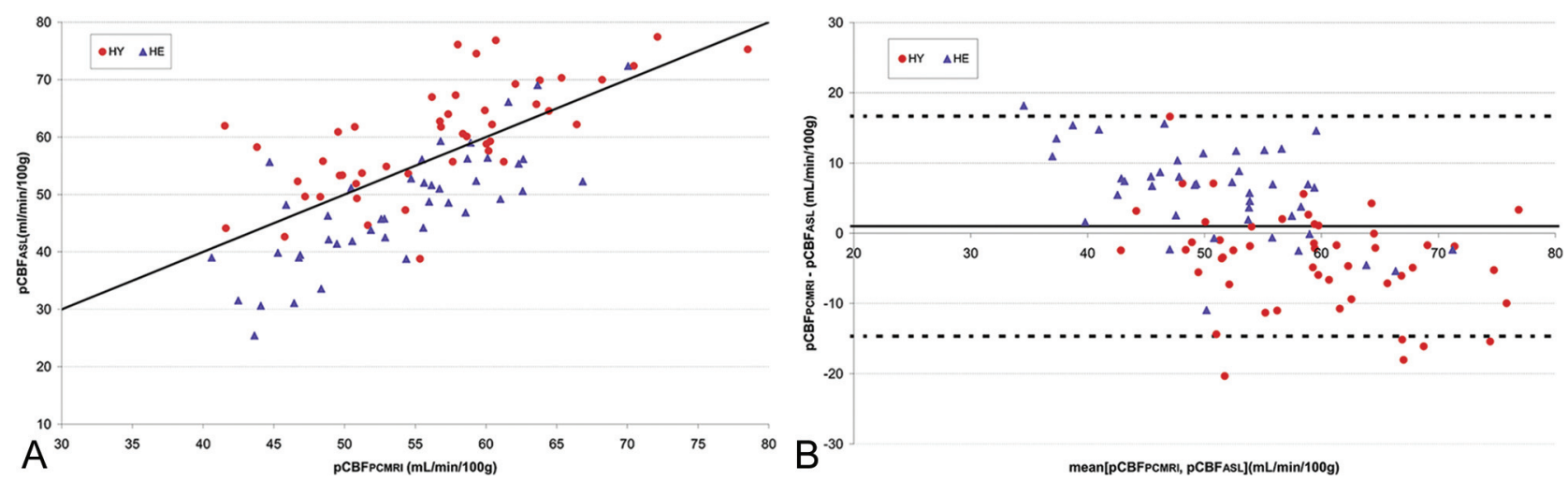

FIGURE. A, Scatterplot of parenchymal cerebral blood flow determined by ASL $\left(\mathrm{PCBF}_{\mathrm{ASL}}\right.$ ) versus PCMRI-determined parenchymal cerebral blood flow $\left(\mathrm{PCBF}_{\mathrm{PCMRI}}\right)$. The solid black line is the identity line. The correlation coefficient $r$ is $0.73(P<.001)$. B, Corresponding Bland-Altman plot. The horizontal dashed lines represent the $95 \%$ confidence intervals of the difference between $\mathrm{PCBF}_{\mathrm{PCMRI}}$ and $\mathrm{PCBF}_{\mathrm{ASL}}$. 
lation with the mean velocities of the VAs $(r=-0.47 ; P<.001$; On-line Fig 2) and ICAs $(r=-0.35 ; P=.001)$.

\section{Dependence of $P C B F_{A S L}$ and $p C B F_{P C M R I}$ on Age and Sex}

$\mathrm{pCBF}_{\mathrm{ASL}}$ values were significantly higher in $\mathrm{HY}$ than in HE subjects $(P<.001$; Table $)$. A similar pattern emerged for $\mathrm{pCBF}_{\mathrm{PCMRI}}$ values, but the difference was less evident $(P=.05$; Table). Therefore, the percent decrease of the mean $\mathrm{pCBF}$ with aging was lower in $\mathrm{pCBF}_{\mathrm{PCMRI}}(-5 \%)$ than in $\mathrm{pCBF}_{\mathrm{ASL}}(-21 \%)$. The $\mathrm{pCBF}_{\mathrm{PCMRI}}$ and $\mathrm{pCBF}_{\mathrm{ASL}}$ values were significantly higher in women ( $\mathrm{pCBF}_{\mathrm{PCMRI}}$, $\left.9 \%\left[P=4 \times 10^{-4}\right] ; \mathrm{pCBF}_{\mathrm{ASL}}, 12 \%[P=.002]\right)$.

\section{DISCUSSION}

Methods for assessing cerebral perfusion by using ASL are available on most modern MR imaging scanners, but their accuracy is still not fully established. Using high-spatial-resolution PCMRI as the reference method, the accuracy of ASL was investigated in this study, and the dependencies on age and sex were quantified and compared. A good correlation was found between the reference method and ASL, but a significant difference between the mean values was observed for both HE (approximately - 11\%) and HY (5\%) subjects. Consequently, the observed effect of aging on pCBF was estimated as much lower in values obtained from PCMRI than in those from ASL ( $5 \%$ vs 21\%). Because of ASL overestimation in HY subjects and underestimation in HE subjects, no significant difference between $\mathrm{pCBF}_{\mathrm{PCMRI}}$ and $\mathrm{pCBF}_{\mathrm{ASL}}$ values was observed in the group as a whole (Table).

In this study, high-resolution PCMRI with an in-plane resolution of $0.35 \mathrm{~mm}$ was used, which represents $>8$ pixels per diameter for the internal carotid and vertebral arteries. With high spatial resolution $(>4$ pixels per diameter) and by using similar MR imaging parameters (velocity encoding, TE, TR, and section thickness) as in the present study, it was shown previously that PCMRI can accurately $(<10 \%$ error) measure the blood flow in ICAs and VAs and thus can be considered a criterion-standard technique for measuring total CBF. $^{14}$

The ASL sequence used in this study had a short MR imaging acquisition time ( $<5$ minutes for whole-brain coverage), and we used a pseudocontinuous arterial-labeling scheme with 3D segmented readout and background suppression, which is considered one of the best ASL approaches for assessing $\mathrm{pCBF} .{ }^{2}$ It is important to emphasize that in this study, the ASL data were obtained with a commercially available ASL sequence, and the CBF estimates were quantified by using the manufacturer's postprocessing software without any additional corrections, as was also done in previous studies. ${ }^{19,25}$ It should be mentioned that the CBF quantification model used in this study was slightly different than the model proposed in a recent consensus article concerning ASL for clinical applications (Appendix). ${ }^{2}$

Jain et $\mathrm{al}^{26}$ reported results from a group of children that were similar to ours (ie, a significant correlation of pCBF values determined by PCMRI and ASL). Other studies have found moderate to good correlations $(r=0.4-0.8)$ between pseudocontinuous ASL and PET imaging for pCBF measurements. ${ }^{4,27,28}$ On the contrary, Henriksen et $\mathrm{al}^{29}$ showed a large underestimation of ASLbased pCBF (75\%) compared with the estimation by PCMRI and no correlation between the 2 methods. One explanation for this result might be that they used a model-free pulsed-ASL method.
The results of our study further support the use of pseudocontinuous ASL. PET is most likely a good method for comparison with ASL, because it is possible to perform intermodal comparisons of global and regional brain perfusion measurements. A recent study found a relatively low correlation between ASL and PET for measuring pCBF in GM at resting state, ${ }^{4}$ but it is not feasible to repeat such a study with a large number of volunteers.

In accordance with the results of our study, previous ASL studies found a difference of mean pCBF (17\%) or perfusion in GM (20\%$30 \%$ ) between HY and HE subjects. ${ }^{5,6}$ In these previous ASL studies, no age-specific postlabeling delay was used, and the postlabeling delays that were used ranged from 800 to $1700 \mathrm{~ms}$. PET and SPECT studies have revealed similar results. ${ }^{9,10}$ Our findings confirm that pCBF decreases with age in healthy adults. However, the magnitude of the decline in $\mathrm{pCBF}$ as determined by ASL was approximately 4 times larger than that determined by PCMRI, and these results bring into question previous observations regarding the magnitude of decrease in ASL-derived pCBF that is associated with healthy aging. Aging causes general brain atrophy and cortical thinning, which may increase the partial volume effects, ${ }^{30,31}$ and aging also leads to increased arterial transit time. ${ }^{32}$ Potentially, such changes influence the accuracy of ASL. ${ }^{5}$ Increasing the postlabeling delay for elderly subjects could remedy some ASL inaccuracies. ${ }^{2}$ Furthermore, the CBF quantification model used in our study (see Appendix and equation 3 ) assumes that the longitudinal relaxation time of gray matter $\left(\mathrm{T}_{\mathrm{GM}}\right)$ and the brain-to-blood partition coefficient $(\lambda)$ are constant. However, previous studies have provided no real consensus with regard to a possible effect of aging on $\mathrm{T}_{\mathrm{GM}} \cdot{ }^{33,34}$ Furthermore, it is known that $\lambda$ values are higher in the neonatal brain than in the adult brain. ${ }^{35}$ Hence, we cannot rule out the possibility that the brain-toblood partition coefficient varies over a life span between 25 and 71 years of age.

Women had higher pCBF $\mathrm{PCMRI}(9 \%)$ and $\mathrm{pCBF}_{\mathrm{ASL}}(12 \%)$ values than the men in this study. Similar results have been reported, with pCBF values being 9\%-15\% higher in women. ${ }^{5,10,36}$ Because various imaging modalities have indicated the same relative difference, it can be regarded as reliable, and it indicates that the accuracy of the ASL method was not affected by differences related to sex. The T1 relaxation of blood $\left(\mathrm{Tl}_{\mathrm{b}}\right)$ can influence the accuracy of ASL perfusion measurements. ${ }^{26,37}$ Previous studies have shown higher mean $\mathrm{T} 1_{\mathrm{b}}$ values $(6 \%-9 \%)$ in women than in men, and the lower blood hematocrit level in women than in men may explain this observed sex difference in mean $\mathrm{T}_{\mathrm{b}} \cdot{ }^{38-40}$ In a previous study, Piechnik et $\mathrm{al}^{40}$ found significantly higher mean $\mathrm{T} 1_{\mathrm{b}}$ values in women than in men ( 1577 vs $1491 \mathrm{~ms}$, respectively). Using equation 3 in the Appendix and $\mathrm{T}_{1 \mathrm{~b}}$ for men and for women, we estimated that the relative sex difference in $\mathrm{pCBF}_{\mathrm{ASL}}$ values in our data decreased from $12 \%$ to approximately $4 \%$, which then is less than the PCMRI findings. In the same study, Piechnik et $\mathrm{al}^{40}$ found no differences in $\mathrm{T}_{\mathrm{b}}$ values between $\mathrm{HY}$ (20-30 years) and HE (60-70 years) subjects, which indicates that the $\mathrm{T} 1_{\mathrm{b}}$ effect is not the dominating factor in explaining the large effect of aging on $\mathrm{PCBF}_{\mathrm{ASL}}$.

Motion artifacts during the ASL scan were not corrected, which might be a source of error in the $\mathrm{PCBF}_{\mathrm{ASL}}$ estimates. Another factor that might influence the ASL perfusion accuracy is the location of the labeling plane. In the present study, the labeling plane was located at the base of the cerebellum and should be 
oriented perpendicularly to the cerebral feeding arteries. This placement was difficult to achieve; manually placing the labeling plane for ASL was not possible, because the current commercial implementation of pCASL does not allow it. Furthermore, the tortuosity of cerebral arteries increases with age, which may partly explain the underestimation of $\mathrm{pCBF}_{\mathrm{ASL}}$ in $\mathrm{HE}$ subjects. ${ }^{41}$ For 5 $\mathrm{HE}$ subjects, $\mathrm{pCBF}_{\mathrm{ASL}}$ values were unreasonably low (ie, of the order of $20-30 \mathrm{~mL} / \mathrm{min} / 100 \mathrm{~g}$; Fig $1 A$ ). When we excluded these HE subjects from the analysis, we observed a minor increase (from 46 to $48 \mathrm{~mL} / \mathrm{min} / 100 \mathrm{~g}$ ) in the mean $\mathrm{pCBF}_{\mathrm{ASL}}$ in $\mathrm{HE}$ subjects, which did not change our main conclusions. Furthermore, we visually inspected the labeling-plane position in these $5 \mathrm{HE}$ subjects with respect to the geometry of the feeding cerebral arteries by using TOF angiography. In 3 subjects, the labeling plane was close to parallel with the VAs, and ASL data showed a very low $\mathrm{CBF}_{\mathrm{ASL}}$ in the posterior region (see example in On-line Fig 3). However, on 2 other $\mathrm{HE}$ subjects with a low $\mathrm{pCBF}_{\mathrm{ASL}}$, the labeling plane was close to perpendicular to both ICAs and VAs, and thus its position should not cause the low $\mathrm{CBF}_{\mathrm{ASL}}$ that we observed in the posterior regions (On-line Fig 3). In future studies, it will be important to investigate in detail how the tortuosity of ICAs and VAs can alter the estimation of $\mathrm{pCBF}$ values with ASL.

The tortuosity of ICAs and VAs is also challenging for the PCMRI method, in which misalignment of the PCMRI plane can cause an underestimation of the total cerebral blood flow. ${ }^{42}$ In our study, this potential problem was partially avoided by careful manual placement of the PCMRI planes in the TOF angiogram. A potential source of pCBF overestimation in PCMRI is the inclusion of extracerebral blood flow of the anterior spinal artery and ophthalmic arteries. The lumen of the spinal artery has been reported to be small (diameter, $<1 \mathrm{~mm}$ ), and the total blood flow rate of the slightly larger ophthalmic artery is approximately $22 \mathrm{~mL} / \mathrm{min}$ in healthy adults. ${ }^{43,44}$ Hence, we estimated that the total blood flow of these extracerebral arteries could represent $3 \%-4 \%$ of potential pCBF overestimation by using our reference PCMRI method.

Finally, pCBF quantification in white matter by ASL is problematic because of the low signal-to-noise ratio ${ }^{45}$ and its long and nonuniform arterial transit time. ${ }^{46,47}$ If white matter pCBF shows a systematic bias, it would affect the mean whole-brain value.

\section{CONCLUSIONS}

For mean parenchymal cerebral blood flow, a high degree of correlation was found between the ASL and PCMRI (reference) methods. For HY adults, the accuracy of pCBF assessment determined by ASL was good with regard to the systematic difference, though the randomized difference against the PCMRI method was outside of the limits according to our criteria. There were both systematic underestimation and a similarly large randomized difference in results for the HE subjects. Consequently, agerelated reductions in $\mathrm{pCBF}$ became augmented with ASL compared with the reference method.

\section{APPENDIX}

The true in-plane spatial resolution of the pCASL sequence was $3.75 \mathrm{~mm} .{ }^{17-19}$ Background suppression pulses were achieved by saturating the imaged volume before labeling and by applying 4 nonselective inversion pulses at $1500 \mathrm{~ms}, 680 \mathrm{~ms}, 248 \mathrm{~ms}$, and 57 ms before readout. ${ }^{48}$ A reference image was obtained $2000 \mathrm{~ms}$ after saturation in the same sequence as the rest of the ASL data.

The following description of the CBF quantification method was provided by the manufacturer of the MR imaging scanner:

$$
\mathrm{CBF}=6000 \lambda\left(1-\mathrm{e}^{-T_{\text {sat }} / \mathrm{Tl}_{\mathrm{GM}}}\right) \frac{\mathrm{e}^{\mathrm{PLD} / \mathrm{Tl}_{\mathrm{b}}}}{2 \alpha \mathrm{T} 1_{\mathrm{b}}\left(1-\mathrm{e}^{-\tau / \mathrm{Tl}}\right) S_{0}},
$$

where PLD is the postlabeling delay time $(1525 \mathrm{~ms}) ; \tau$ is the labeling duration $(1500 \mathrm{~ms}) ; \alpha$ is a combination of inversion efficiency $(0.8)$ and background suppression efficiency $(0.75)^{48}$ resulting in an overall labeling efficiency of 0.6 ; $\lambda$ is the tissue-to-blood partition coefficient $(0.9 \mathrm{~mL} / \mathrm{g})^{35} ; \mathrm{T}_{\mathrm{b}}$ and $\mathrm{T} 1_{\mathrm{GM}}$ are the longitudinal relaxation times of blood (1600 ms) and GM (1200 ms), respectively; $T_{\text {sat }}$ is the saturation time $(2000 \mathrm{~ms})^{18} ; S_{0}$ is the reference image signal (obtained voxelwise); and $\Delta S$ is the ASL difference image signal. The scaling factor 6000 was used to convert to CBF units $(\mathrm{mL} / \mathrm{min} / 100 \mathrm{~g})$. In our study, it was assumed that WM perfusion can be calculated by using the model described above and setting parameters. Compared with the quantification proposed by Alsop et al, ${ }^{2}$ a term for compensation of the imperfect relaxation in the reference image is added.

Disclosures: Ronnie Wirestam—RELATED: Grant: Swedish Research Council,* Comments: Government funding for part of my salary as university professor. Anders Eklund-RELATED: Grant: Swedish Research Council.* *Money paid to institution.

\section{REFERENCES}

1. Williams DS, Detre JA, Leigh JS, et al. Magnetic resonance imaging of perfusion using spin inversion of arterial water. Proc Natl Acad Sci U S A 1992;89:212-16 CrossRef Medline

2. Alsop DC, Detre JA, Golay X, et al. Recommended implementation of arterial spin-labeled perfusion MRI for clinical applications: a consensus of the ISMRM perfusion study group and the European consortium for ASL in dementia. Magn Reson Med 2014 Apr 8. [Epub ahead of print] CrossRef Medline

3. Dai W, Garcia D, de Bazelaire C, et al. Continuous flow-driven inversion for arterial spin labeling using pulsed radio frequency and gradient fields. Magn Reson Med 2008;60:1488-97 CrossRef Medline

4. Heijtel DF, Mutsaerts HJ, Bakker E, et al. Accuracy and precision of pseudo-continuous arterial spin labeling perfusion during baseline and hypercapnia: a head-to-head comparison with ${ }^{15} \mathrm{O}_{2} \mathrm{O}$ positron emission tomography. Neuroimage 2014;92:182-92 CrossRef Medline

5. Parkes LM, Rashid W, Chard DT, et al. Normal cerebral perfusion measurements using arterial spin labeling: reproducibility, stability, and age and gender effects. Magn Reson Med 2004;51:736-43 CrossRef Medline

6. Asllani I, Habeck C, Borogovac A, et al. Separating function from structure in perfusion imaging of the aging brain. Hum Brain Mapp 2009;30:2927-35 CrossRef Medline

7. Biagi L, Abbruzzese A, Bianchi MC, et al. Age dependence of cerebral perfusion assessed by magnetic resonance continuous arterial spin labeling. J Magn Reson Imaging 2007;25:696-702 CrossRef Medline

8. Chen JJ, Rosas HD, Salat DH. Age-associated reductions in cerebral blood flow are independent from regional atrophy. Neuroimage 2011;55:468-78 CrossRef Medline

9. Leenders KL, Perani D, Lammertsma AA, et al. Cerebral blood flow, blood volume and oxygen utilization. Normal values and effect of age. Brain 1990;113:27-47 CrossRef Medline

10. Slosman DO, Chicherio C, Ludwig C, et al. (133)Xe SPECT cerebral blood flow study in a healthy population: determination of T-scores. J Nucl Med 2001;42:864-70 Medline

11. Meltzer CC, Cantwell MN, Greer PJ, et al. Does cerebral blood flow decline in healthy aging? A PET study with partial-volume correction. J Nucl Med 2000;41:1842-48 Medline 
12. Aanerud J, Borghammer P, Chakravarty MM, et al. Brain energy metabolism and blood flow differences in healthy aging. J Cereb Blood Flow Metab 2012;32:1177-87 CrossRef Medline

13. Aslan S, Xu F, Wang PL, et al. Estimation of labeling efficiency in pseudocontinuous arterial spin labeling. Magn Reson Med 2010;63: 765-71 CrossRef Medline

14. Wåhlin A, Ambarki K, Hauksson J, et al. Phase contrast MRI quantification of pulsatile volumes of brain arteries, veins, and cerebrospinal fluids compartments: repeatability and physiological interactions. J Magn Reson Imaging 2012;35:1055-62 CrossRef Medline

15. Valverde S, Oliver A, Cabezas M, et al. Comparison of 10 brain tissue segmentation methods using revisited IBSR annotations. J Magn Reson Imaging 2015;41:93-101 CrossRef Medline

16. Folstein MF, Folstein SE, McHugh PR. “Mini-mental state.” A practical method for grading the cognitive state of patients for the clinician. J Psychiatr Res 1975;12:189-98 CrossRef Medline

17. Pienaar R, Paldino MJ, Madan N, et al. A quantitative method for correlating observations of decreased apparent diffusion coefficient with elevated cerebral blood perfusion in newborns presenting cerebral ischemic insults. Neuroimage 2012;63:1510-18 CrossRef Medline

18. Järnum H, Steffensen EG, Knutsson L, et al. Perfusion MRI of brain tumours: a comparative study of pseudo-continuous arterial spin labelling and dynamic susceptibility contrast imaging. Neuroradiology 2010;52:307-17 CrossRef Medline

19. Mutsaerts HJ, Steketee RM, Heijtel DF, et al. Inter-vendor reproducibility of pseudo-continuous arterial spin labeling at 3 Tesla. PLoS One 2014;9:e104108 CrossRef Medline

20. Melzer TR, Watts R, MacAskill MR, et al. Arterial spin labelling reveals an abnormal cerebral perfusion pattern in Parkinson's disease. Brain 2011;134:845-55 CrossRef Medline

21. Rajapakse JC, Giedd JN, Rapoport JL. Statistical approach to segmentation of single-channel cerebral MR images. IEEE Trans Med Imaging 1997;16:176-86 CrossRef Medline

22. Buxton RB, Frank LR, Wong EC, et al. A general kinetic model for quantitative perfusion imaging with arterial spin labeling. Magn Reson Med 1998;40:383-96 CrossRef Medline

23. Torack RM, Alcala H, Gado M, et al. Correlative assay of computerized cranial tomography CCT, water content and specific gravity in normal and pathological postmortem brain. J Neuropathol Exp Neurol 1976;35:385-92 CrossRef Medline

24. Bland JM, Altman DG. Statistical methods for assessing agreement between two methods of clinical measurement. Lancet 1986;1: 307-10 Medline

25. Bron EE, Steketee RM, Houston GC, et al; Alzheimer's Disease Neuroimaging Initiative. Diagnostic classification of arterial spin labeling and structural MRI in presenile early stage dementia. Hum Brain Mapp 2014;35:4916-31 CrossRef Medline

26. Jain V, Duda J, Avants B, et al. Longitudinal reproducibility and accuracy of pseudo-continuous arterial spin-labeled perfusion MR imaging in typically developing children. Radiology 2012;263: 527-36 CrossRef Medline

27. van Golen LW, Kuijer JP, Huisman MC, et al. Quantification of cerebral blood flow in healthy volunteers and type 1 diabetic patients: comparison of MRI arterial spin labeling and [(15)O]H2O positron emission tomography (PET). J Magn Reson Imaging 2014;40: 1300-09 CrossRef Medline

28. Zhang K, Herzog H, Mauler J, et al. Comparison of cerebral blood flow acquired by simultaneous [15O]water positron emission tomography and arterial spin labeling magnetic resonance imaging. J Cereb Blood Flow Metab 2014;34:1373-80 CrossRef Medline

29. Henriksen OM, Larsson HB, Hansen AE, et al. Estimation of intersubject variability of cerebral blood flow measurements using MRI and positron emission tomography. J Magn Reson Imaging 2012;35: 1290-99 CrossRef Medline

30. Kety SS. Human cerebral blood flow and oxygen consumption as related to aging. J Chronic Dis 1956;3:478-86 CrossRef Medline

31. Good CD, Johnsrude IS, Ashburner J, et al. A voxel-based morphometric study of ageing in $\mathbf{4 6 5}$ normal adult human brains. Neuroimage 2001;14:21-36 CrossRef Medline

32. Scheel $P$, Ruge $C$, Schöning $M$. Flow velocity and flow volume measurements in the extracranial carotid and vertebral arteries in healthy adults: reference data and the effects of age. Ultrasound Med Biol 2000;26:1261-66 CrossRef Medline

33. Cho S, Jones D, Reddick WE, et al. Establishing norms for age-related changes in proton T1 of human brain tissue in vivo. Magn Reson Imaging 1997;15:1133-43 CrossRef Medline

34. Breger RK, Yetkin FZ, Fischer ME, et al. T1 and T2 in the cerebrum: correlation with age, gender, and demographic factors. Radiology 1991;181:545-47 CrossRef Medline

35. Herscovitch P, Raichle ME. What is the correct value for the brainblood partition coefficient for water? J Cereb Blood Flow Metab 1985; 5:65-69 CrossRef Medline

36. Esposito G, Van Horn JD, Weinberger DR, et al. Gender differences in cerebral blood flow as a function of cognitive state with PET. J Nucl Med 1996;37:559-64 Medline

37. Varela M, Hajnal JV, Petersen ET, et al. A method for rapid in vivo measurement of blood T1. NMR Biomed 2011;24:80-88 CrossRef Medline

38. Wu WC, Jain $\mathrm{V}, \mathrm{Li}$ C, et al. In vivo venous blood $\mathrm{T} 1$ measurement using inversion recovery true-FISP in children and adults. Magn Reson Med 2010;64:1140-47 CrossRef Medline

39. Qin Q, Strouse JJ, van Zijl PC. Fast measurement of blood T1 in the human jugular vein at 3 Tesla. Magn Reson Med 2011;65:1297-304 CrossRef Medline

40. Piechnik SK, Ferreira VM, Lewandowski AJ, et al. Normal variation of magnetic resonance $\mathrm{T} 1$ relaxation times in the human population at 1.5 T using ShMOLLI. J Cardiovasc Magn Reson 2013;15:13 CrossRef Medline

41. Bullitt E, Zeng D, Mortamet B, et al. The effects of healthy aging on intracerebral blood vessels visualized by magnetic resonance angiography. Neurobiol Aging 2010;31:290-300 CrossRef Medline

42. Zhao M, Charbel FT, Alperin N, et al. Improved phase-contrast flow quantification by three-dimensional vessel localization. Magn Reson Imaging 2000;18:697-706 CrossRef Medline

43. Sheehy NP, Boyle GE, Meaney JF. Normal anterior spinal arteries within the cervical region: high-spatial-resolution contrast-enhanced three-dimensional MR angiography. Radiology 2005;236: 637-41 CrossRef Medline

44. Ambarki K, Hallberg P, Jóhannesson G, et al. Blood flow of ophthalmic artery in healthy individuals determined by phase-contrast magnetic resonance imaging. Invest Ophthalmol Vis Sci 2013;54: 2738-45 CrossRef Medline

45. van Osch MJ, Teeuwisse WM, van Walderveen MA, et al. Can arterial spin labeling detect white matter perfusion signal? Magn Reson Med 2009;62:165-73 CrossRef Medline

46. Pohmann R. Accurate, localized quantification of white matter perfusion with single-voxel ASL. Magn Reson Med 2010;64:1109-13 CrossRef Medline

47. Lu K, Liu T, Wong EC, et al. Regional white matter perfusion measurement using an optimized pseudo-continuous ASL MRI. In: Proceedings of the 17th Annual Meeting of the International Society of Magnetic Resonance in Medicine [abstract 4401]. Honolulu, Hawaii. April $18-24,2009$

48. Garcia DM, Duhamel G, Alsop DC. Efficiency of inversion pulses for background suppressed arterial spin labeling. Magn Reson Med 2005;54:366-72 CrossRef Medline 